\title{
Blue sclerae with keratoglobus and brittle cornea
}

\author{
N. D. GREGORATOS, G. S. BARTSOCAS, AND K. PAPAS \\ Aghia Sophia Children's Hospital, Athens, Greece
}

Blue sclerae are usually found in association with inherited disorders of the mesodermal tissues. They are a consistent sign of osteogenesis imperfecta, but they are also present in the Ehlers-Danlos syndrome and Marfan's syndrome. We report another hereditary condition of blue sclerae associated with keratoglobus and brittle cornea, possibly representing a new syndrome.

\section{Case report}

A 4-year-old boy was admitted to the Aghia Sophia Children's Hospital because of a perforating injury of the right eye after a minor accident.

The corneo-scleral wound was large, and during the operation, which was performed immediately the cornea was found to be very fragile and thin, making suturing extremely difficult. The wound re-opened once, but finally healed.

\section{Examination}

Both eyes were large and bulging, the sclerae were blue, there was keratoglobus and central corneal opacities ( 2 to $3 \mathrm{~mm}$. in diameter). The cornea of the left eye was $12 \mathrm{~mm}$. in diameter and the intraocular pressure was within normal limits when measured on several occasions. The fundus was not visible.

\section{History}

This was unremarkable except for an arrested hydrocephalus with no abnormal central nervous system signs or mental retardation. Psychomotor development was normal for the patient's age.

Family history (Figure)

The father was 33 and the mother 25 years old. The father was healthy. The mother, who had slightly blue sclerae, had had three pregnancies; the first child was a stillborn girl, the second was the proband, and the third was a 3-year-old girl with blue sclerae.

There was parental consanguinity in that the parents were second-cousins. All members of the family were dark-haired. Absence of bone fractures or deafness or any significant family history or clinical signs excluded osteogenesis, the Ehlers-Danlos syndrome and Marfan's syndrome.

\section{Discussion}

The present case appears to represent a hereditary disorder characterized by blue sclerae, keratoglobus, and brittle cornea. A combination of blue sclerae with brittle cornea and red hair was described as a syndrome by Stein, Lazar, and Adam ( 1968) from Israel.

This Greek family included two children with blue sclerae, one of them also having brittle cornea and keratoglobus. The parental consanguinity suggests an autosomal recessive pattern of inheritance, such as that found by Stein and others (1968), whose large 


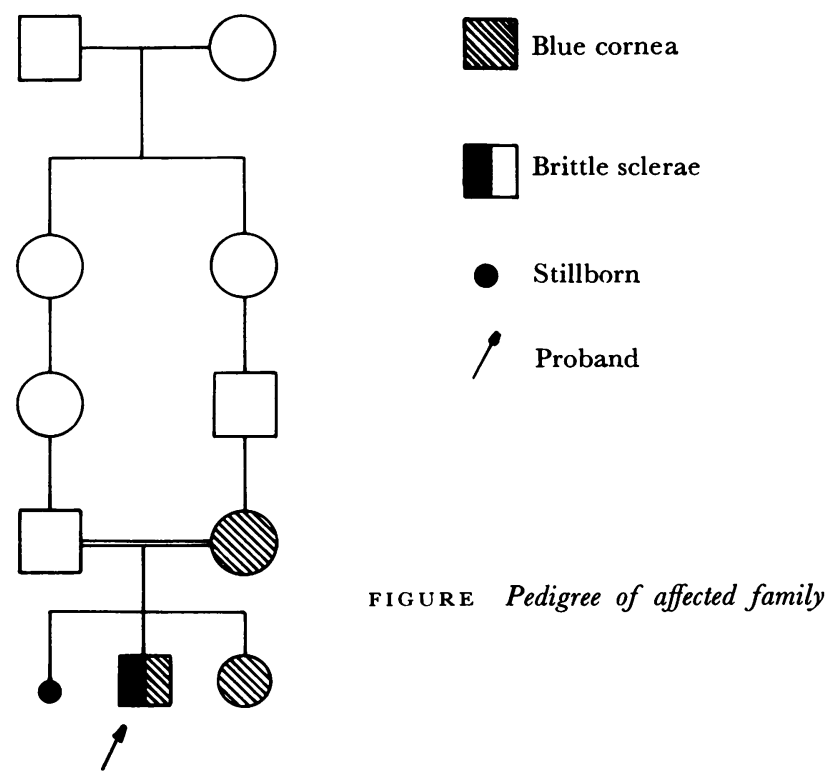

pedigree showed brittle corneae in males, while the females had blue sclerae only. In our family there were only the two children affected, but the boy had brittle cornea and keratoglobus, while the female had blue sclerae only. This may suggest a predisposing factor leading to brittle corneae in males only, but does not exclude an X-linked pattern of inheritance.

The large extension of the perforating wound, and the difficulty in suturing, were the result of the thin and brittle cornea and sclera. Duke-Elder (1964) quoted Buchanan's estimation that, in blue sclerae, the thickness is reduced to one-third of normal and that of the cornea to three-fifths of normal. Ruedemann (1953) stated that the chief histological finding in cases with blue sclerae was a thinning and breaking-down of the collagen.

Arkin ( 1964 ), referring to the appearance of keratoglobus, stated that he had found only two references describing the co-existence of keratoglobus with blue sclerae (Tucker, I959).

Keratoglobus often creates diagnostic difficulties. In megalocornea the only change occurs in the dimensions of the cornea, but in keratoglobus there are changes in the thickness and appearance of the cornea.

Badtke (I94I) reported the presence of blue sclerae with keratoconus. In keratoconus the thinning involves mainly the apex of the cornea, but in keratoglobus the whole cornea is involved.

The enlarged eyes and the corneal opacities could be diagnosed as buphthalmos, but the absence of increased intraocular pressure, tears in Descemet's membrane, and corneal oedema favour the diagnosis of keratoglobus.

\section{Summary}

A Greek family is described in which the mother and two children had blue sclerae. The older child, a boy, also had brittle cornea with keratoglobus. Parental consanguinity was present, and an autosomal recessive pattern of inheritance or an X-linked gene, because of the mother's blue sclerae, is suggested as the cause of this syndrome. 


\section{References}

ARKIN, w. (1964) Amer. J. Ophthal., 58, 678

BADTKE, G. (1941) Klin. Mbl. Augenheilk., 106, 585

DUKE-ELDER, s. (1964) "System of Ophthalmology", vol. 3, pt 2, “Congenital Deformities", p. 539.

Kimpton, London

ruedemann, A. D. (1953) A.M.A. Arch. Ophthal., 49, 6

Stein, R., LAZAR, M., and ADAM, A. (1968) Amer. F. Ophthal., 66, 67

TUGKER, D. P. (1959) Ibid., 47, 345 